Short Report

\title{
Pediatric Thoracoscopic Repair of Diaphragmatic Herniation Following Liver Transplantation
}

Inês Pessanha ${ }^{1,2,}{ }^{*}$, Catarina Cunha ${ }^{1,2}$, Cláudia Piedade ${ }^{1,2}$, Emanuel Furtado ${ }^{2}$, Maria Francelina Lopes ${ }^{1,2,3}$

1. Department of Pediatric Surgery, Hospital Pediátrico, Centro Hospitalar e Universitário de Coimbra, Coimbra, Portugal; E-Mails: ipessanha3@gmail.com; catarinacrc@hotmail.com; claudiacpiedade@gmail.com; mfrancelina@yahoo.com

2. Pediatric and Adult Liver Transplantation Unit, Centro Hospitalar e Universitário de Coimbra, Coimbra, Portugal; E-Mail: esbfurtado@gmail.com

3. Faculty of Medicine, University of Coimbra, Coimbra, Portugal

* Correspondence: Inês Pessanha; E-Mail: ipessanha3@gmail.com

Academic Editor: Haval Shirwan

Special Issue: Abdominal Organ Transplantation

OBM Transplantation

2021, volume 5, issue 1

doi:10.21926/obm.transplant. 2101131
Received: August 09, 2020

Accepted: December 17, 2020

Published: January 05, 2021

\begin{abstract}
Diaphragmatic Hernia (DH) after Liver Transplantation (LT) is a rare complication with unclear pathophysiology. Among $261 \mathrm{LT}$, we recognized six DH during the post transplant period (2.30\%). All patients with $\mathrm{DH}$ had received a left lateral segment (LLS) reduced graft. The mean graft weight was $340 \mathrm{~g}$ with a mean graft-to-recipient body weight ratio (GBWR) of $4.20 \%$. LLS grafts, a GBWR $>4 \%$, previous abdominal surgery and direct trauma during surgery can be enumerated as potential risk factors for DH post-LT. These children underwent prompt surgical intervention to $\mathrm{DH}$ without complications. Three patients were treated via laparotomy and three by thoracoscopy. No clinical recurrences were accounted at a mean follow up of 5 years. Historically, the treatment has always been surgical repair via laparotomy but the use of minimally invasive techniques in pediatric surgery has been increasing, and the
\end{abstract}

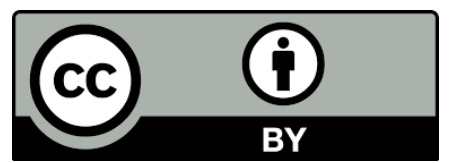

(C) 2021 by the author. This is an open access article distributed under the conditions of the Creative Commons by Attribution License, which permits unrestricted use, distribution, and reproduction in any medium or format, provided the original work is correctly cited. 
thoracoscopic approach for DH can bring advantages. The patients in which the thoracoscopic approach was used had shorter operative times and a faster recovery with better cosmetic results. As previous surgical manipulation had been done to the abdominal cavity, thoracoscopy seems to be a safe approach in DH in pediatric LT recipients.

\section{Keywords}

Diaphragmatic; hernia; liver transplantation; thoracoscopy

\section{Introduction}

Pediatric liver transplantation (LT) is a life-saving procedure. However, factors such as low weight and poor medical standing put children at the forefront of post-LT diaphragmatic hernia (LTDH), with an incidence of $0.75-3.2 \%$ [1-5].

The pathophysiology of this complication remains poorly understood, but several possible contributing factors have been proposed for the complication: diaphragm thinness due to low weight and severe malnutrition; direct trauma during the operation; elevated abdominal pressure caused by an increased graft-to-recipient body weight ratio (GBWR); medial positioning of a partial liver graft which results in a posterolateral "free space" where the bowel is usually lying $[1,6]$.

Earl et al. suggested that almost half of bowel obstruction cases requiring surgical intervention in liver pediatric recipients are caused by LTDH [7]. This highlights the importance of prompt recognition and urgent surgical interventions [1, 2].

Historically, treatment has been via open surgical repair [2]. However, minimally invasive techniques (MITs) for diaphragmatic hernia (DH) repair are currently thriving due to the experience and expertise of pediatric surgeons on the successful thoracoscopic correction of Congenital Diaphragmatic Hernia (CDH) [2].

The primary goal of this study is to characterize the population of patients diagnosed with a diaphragmatic hernia after liver transplantation in our center and to report our experience on an MIT approach in the management of this complication in pediatric recipients.

\section{Materials and Methods}

We retrospectively reviewed a total of 261 liver transplants (LT). Among the patients diagnosed with LTDH, we assessed the following information: age at the time of the LT (months), sex, weight at the time of the LT, diagnosis, previous surgery, graft type, biliary anastomosis type, GBWR, the interval from $\mathrm{LT}$ to $\mathrm{DH}$, presenting symptoms, screening method, $\mathrm{DH}$ characterization (including the size of the defect and its content), procedure performed and subsequent follow-up.

A descriptive statistical analysis of the patient characteristics was performed. The qualitative variables, such as frequencies and percentages, were described. The quantitative variables were expressed as means, standard deviations, and ranges. The database used was created under the guidelines of the institution's local ethics committee, and the study was conducted according to the principles established in the declaration of Helsinki. 
OBM Transplantation 2021; 5(1), doi:10.21926/obm.transplant.2101131

\section{Results}

Among $261 \mathrm{LT}$, we recognized six $\mathrm{DH}$ during the post-transplant period (2.30\%). Table 1 summarizes information about patient characteristics. 
Table 1 LT Patients Characteristics.

\begin{tabular}{|c|c|c|c|c|c|c|c|c|c|c|}
\hline $\begin{array}{l}\text { Patient } \\
\text { (N) }\end{array}$ & $\begin{array}{l}\text { Age at LT } \\
\text { (years) }\end{array}$ & $\begin{array}{l}\text { Weight } \\
\text { (kg) }\end{array}$ & $\begin{array}{c}\text { GBWR } \\
(\%)\end{array}$ & Diagnosis & $\begin{array}{l}\text { Previous } \\
\text { surgery }\end{array}$ & $\begin{array}{l}\text { Graft } \\
\text { type }\end{array}$ & Symptoms & $\begin{array}{l}\text { Time to LTDH } \\
\text { (months) }\end{array}$ & $\begin{array}{l}\text { Surgical } \\
\text { approach }\end{array}$ & $\begin{array}{l}\text { Bowel } \\
\text { resection }\end{array}$ \\
\hline 1 & 0.3 & 5.5 & & EHBA & Kasai & LLS & $\begin{array}{c}\text { Respiratory distress } \\
+ \text { Fever }\end{array}$ & 7 & Laparotomy & No \\
\hline 2 & 1 & 8.3 & 4.1 & EHBA & Kasai & LLS & Incidental finding & 3 & Laparotomy & No \\
\hline 3 & 0.8 & 5.6 & 6.2 & EHBA & Kasai & LLS & $\begin{array}{c}\text { Respiratory distress } \\
+ \text { Hypoxia + Fever }\end{array}$ & 3 & Laparotomy & No \\
\hline 4 & 0.6 & 8.0 & 4.0 & EHBA & $\begin{array}{l}\text { Kasai | Small } \\
\text { bowel resection } \\
\text { after perforation }\end{array}$ & LLS & Respiratory distress & 6 & Thoracoscopy & No \\
\hline 5 & 1.8 & 10.7 & 3.55 & EHBA & CardiacSurgery & LLS & Incidental finding & 3 & Thoracoscopy & No \\
\hline 6 & 0.3 & 5.8 & 3.17 & EHBA & Kasai & LLS & Bowel obstruction & 1 & $\begin{array}{l}\text { Thoracoscopy } \\
+ \text { Laparotomy }\end{array}$ & Yes \\
\hline
\end{tabular}

Notes: LT-Liver transplant; GBWR-Graft-to-recipient body weight ratio; EHBA-Extrahepatic biliary atresia; LLS-Left lateral segment; LTDH-Liver Transplant Diaphragmatic Hernia. 
At the time of $L T$, the mean age of all the patients was one year, and all patients were within the $25^{\text {th }}$ percentile for weight. Average weight of $7.4 \mathrm{~kg}$ (range: $5.5-10.7 \mathrm{~kg}$ ) was observed. All six patients received a left lateral segment (LLS) graft, with a mean GBWR of $4.2 \pm 1.7 \%$.

The average time until the LTDH presentation was four months. The symptoms observed at diagnosis were respiratory distress $(n=3)$ and bowel obstruction $(n=1)$, and in others were incidental $(n=2)$. Figure 1 represents radiologic findings of the LTDH at the diagnosis of the CT scan (for case $6)$.
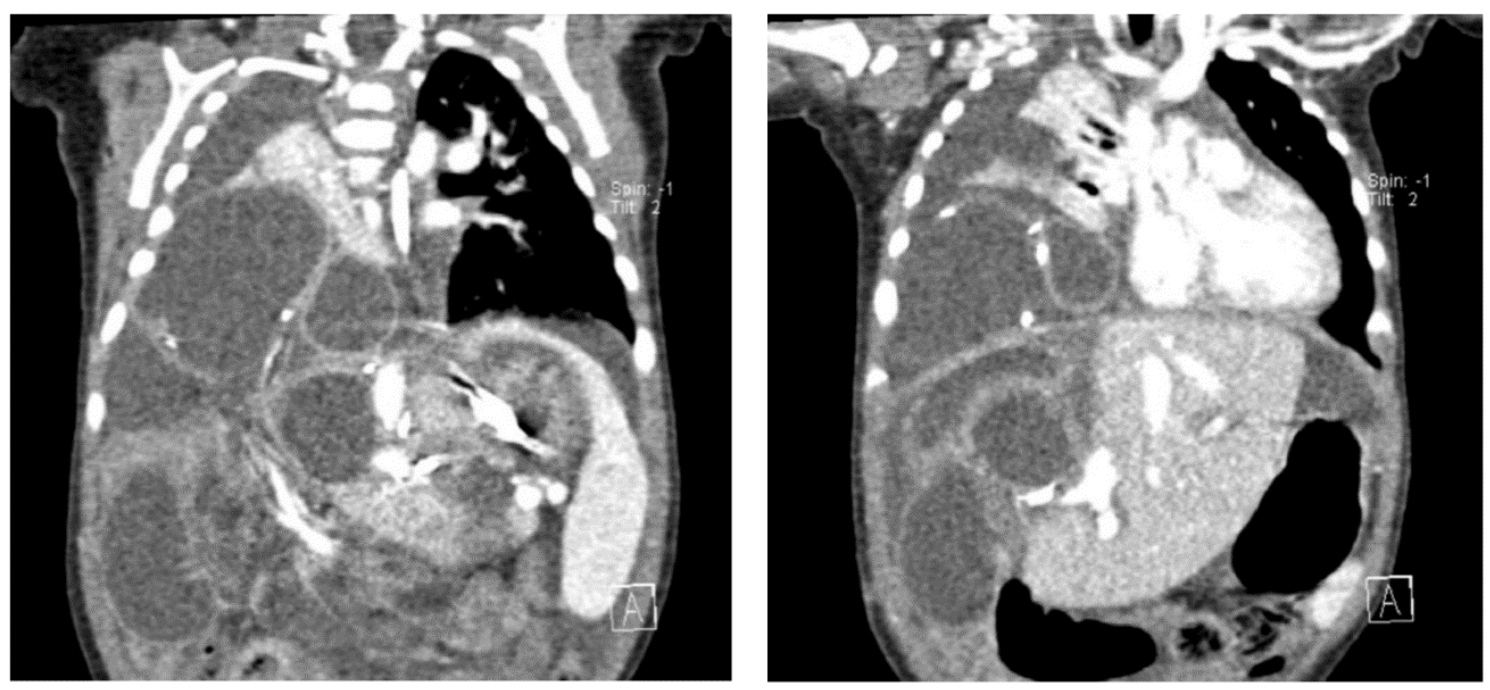

Figure 1 Radiologic findings representative of the LTDH on diagnosis (CT-Scan).

All six patients underwent surgical repair at the time of diagnosis; their diaphragmatic defect after bowel reduction was closed. Half $(n=3)$ of LTDH cases were approached by laparotomy, and the other half $(n=3)$ by thoracoscopy. One case required conversion to laparotomy due to bowel ischemia and perforation.

In the thoracoscopy procedure, the patients were placed in a left decubitus position with roll support placed beneath the thoracoabdominal transition to elevate the diaphragm. The 30 o camera trocar was introduced in the mid-axillary line. Carbon dioxide was insufflated to achieve an intrathoracic pressure of $5 \mathrm{mmHg}$ with a minimal flow $(0.5 \mathrm{~L} / \mathrm{min})$. This insufflation of carbon dioxide along with tilting the operating table helped reduce the herniated viscera. Two additional trocars were placed in the anterior axillary line and behind the scapula tip. Gentle manipulation of the herniated bowel, with blunt forceps, allowed reduction/movement back into the abdominal cavity. Then, the primary repair was accomplished with interrupted horizontal mattress sutures using a non-absorbable thread (Ethibond ${ }^{\circledR} 2.0$ ). The intraoperative mean hernia hole diameter was $3.8 \mathrm{~cm}$ (range: $1.5-7.5 \mathrm{~cm}$ ). The thoracoscopic approach had a shorter operative duration (mean: $2 \mathrm{~h} 45$ $\mathrm{min}$ ) compared with the open procedure (mean: $3 \mathrm{~h} 55 \mathrm{~min}$ ). Figure 2 depicts an intraoperative view of the thoracoscopic approach. 

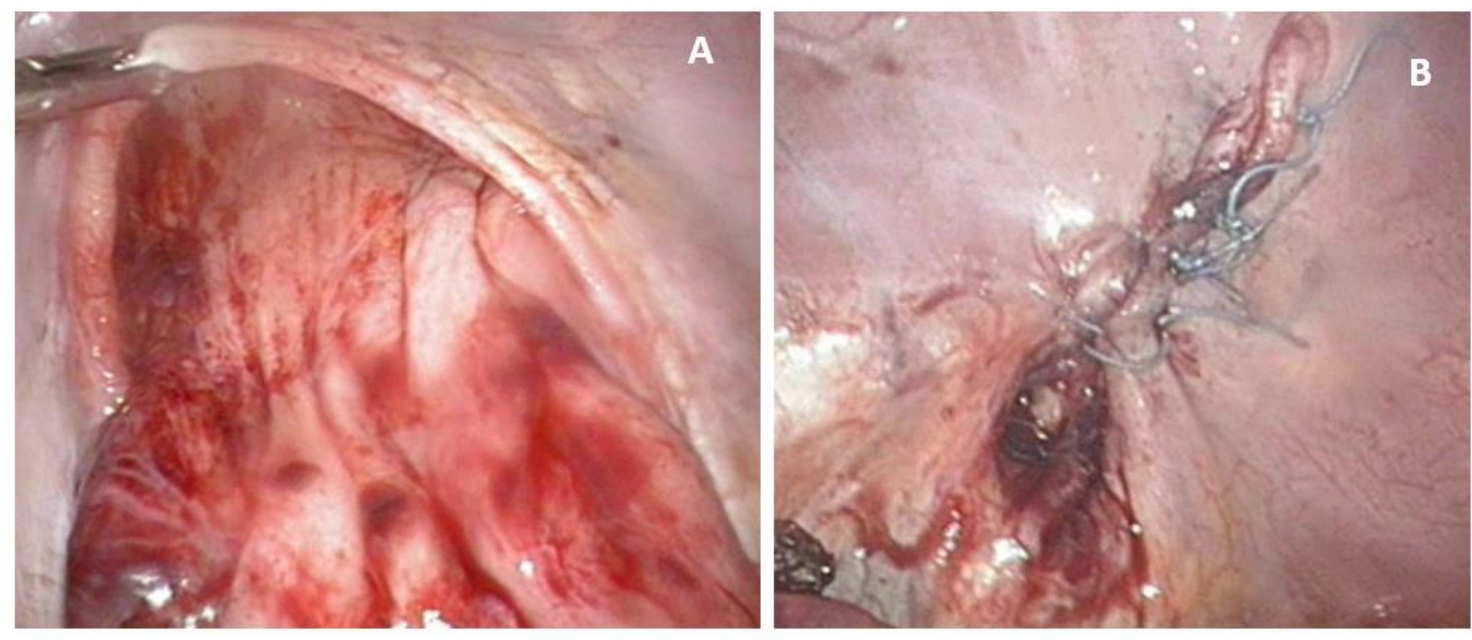

Figure 2 Radiologic findings representative of the LTDH on diagnosis (CT-scan). A: Intraoperative view of the hernia contents and the diaphragm defect. B: Intraoperative view of almost finished diaphragm suture.

Postoperative courses were insignificant except for case no. 6, whose postoperative recovery got complicated by sepsis. Patients with a thoracoscopic approach were discharged on the 5th postoperative day. For the remaining, hospital discharge occurred on an average on the 7th day. Apart from the shorter operative times and a faster recovery, patients with the thoracoscopic approach had better cosmetic results also.

No clinical recurrences or further complications were detected at a mean follow-up of five years (minimum of 13 months). In the current study, no association between the LTDH and mortality was established.

\section{Discussion and Conclusion}

There is no consensus on the best approach for $\mathrm{DH}$ repair. Lam et al. reported that approximately $20 \%$ of the LTDH would require bowel resection and argued that an abdominal open approach would allow better exploration [8]. Another disadvantage of thoracoscopy is that it may offer some technical limitations, such as the mobilization of the posterior muscular rim [9]. There are very few described cases of LTDH managed by thoracoscopy in the literature $[1,2,4]$. Furthermore, among nearly 50 cases published about LTDH, only 3 were approached by thoracoscopy $[2,4,5,10]$.

Nevertheless, thoracoscopy has gained popularity among pediatric surgeons. MITs in the repair of $\mathrm{CDH}$ have brought some tangible advantages such as reduced postoperative pain, better cosmetic results, and reduced morbidity, namely postoperative ileus, adhesion, and scar formation [2].

As mentioned above, thoracoscopy is an easier and faster way to locate and address the diaphragmatic defect, since no previous surgical manipulation was performed in the thoracic cavity [2]. Earlier, surgeries under the abdominal approach threw several challenges such as less clear planes and more adhesions, making it more difficult to access the diaphragm clearly and increasing the risk of iatrogenic injury. Furthermore, steroids and other immunosuppressive therapies have been associated with impaired wound healing, which poses a greater risk of incisional hernias [4, 5]. Thus, MITs improve cosmetic results and probably reduce the incidence of incisional hernias. After 
surgical correction, recurrence seems to be uncommon [1]. Fortunately, none of our patients has a recurrence, establishing the strength of our methodology.

Overall, based on our findings, it is propounded that the awareness of LTDH might prompt pediatric surgeons to reduce its incidence by performing less traumatic dissection and more careful bleeding control during LT. Moreover, an initial thoracoscopic approach allows not only the easiest approach to the defect but also better cosmetic results with a faster postoperative recovery while it does not jeopardize identification of ischemic bowel and conversion to open surgery.

\section{Author Contributions}

Planning, conduct, reporting, conception and design, acquisition of data: IP, CC, CP, EF, MFL. Analysis and interpretation of data: IP, CC, CP, MFL. Patient management: CC, CP, EF, MFL.

\section{Competing Interests}

The authors have declared that no competing interests exist.

\section{References}

1. Cortes M, Tapuria N, Khorsandi SE, Ibars EP, Vilca-Melendez H, Rela M, et al. Diaphragmatic hernia after liver transplantation in children: Case series and review of the literature. Liver Transpl. 2014; 20: 1429-1435.

2. Lee $\mathrm{S}$, Seo JM, Younes AE, Oh CY, Lee SK. Thoracoscopic approach for repair of diaphragmatic hernia occurring after pediatric liver transplant. Medicine (Baltimore). 2015; 94: e1376.

3. Kirnap M, Akdur A, Ozcay F, Soy E, Coskun M, Moray G, et al. Diaphragmatic hernia after pediatric liver transplant. Exp Clin Transplant. 2015; 13: 471-474.

4. Karakas S, Sahin TT, Kutluturk K, Otan E, Baskiran A, Sarici KB, et al. Diaphragmatic hernias after pediatric liver transplantation: Experience of a high-volume transplant center. Pediatr Transplant. 2020; 24: e13684.

5. Emamaullee JA, Nekrasov V, Gilmour S, Kneteman N, Yanni G, Kohli R, et al. Case series and systematic review of acquired diaphragmatic hernia after liver transplantation. Pediatr Transplant. 2018; 22: e13296.

6. McCabe AJ, Orr JD, Sharif K, De Ville de Goyet J. Right-sided diaphragmatic hernia in infants after liver transplantation. J Pediatr Surg. 2005; 40: 1181-1184.

7. Earl TM, Wellen JR, Anderson CD, Nadler M, Doyle MM, Shenoy SS, et al. Small bowel obstruction after pediatric liver transplantation: The unusual is the usual. J Am Coll Surg. 2011; 212: 62-67.

8. Lam HD, Mejia J, Soltys KA, Sindhi R, Mazariegos G, Bond G. Right diaphragmatic hernia after liver transplant in pediatrics: A case report and review of the literature. Pediatr Transplant. 2013; 17: E77-E80.

9. Shigeta T, Sakamoto S, Kanazawa H, Fukuda A, Kakiuchi T, Karaki C, et al. Diaphragmatic hernia in infants following living donor liver transplantation: Report of three cases and a review of the literature. Pediatr Transplant. 2012; 16: 496-500. 
10. Esposito F, Lim C, Salloum C, Osseis M, Lahat E, Compagnon P, et al. Diaphragmatic hernia following liver resection: Case series and review of the literature. Ann Hepatobiliary Pancreat Surg. 2017; 21: 114-121.

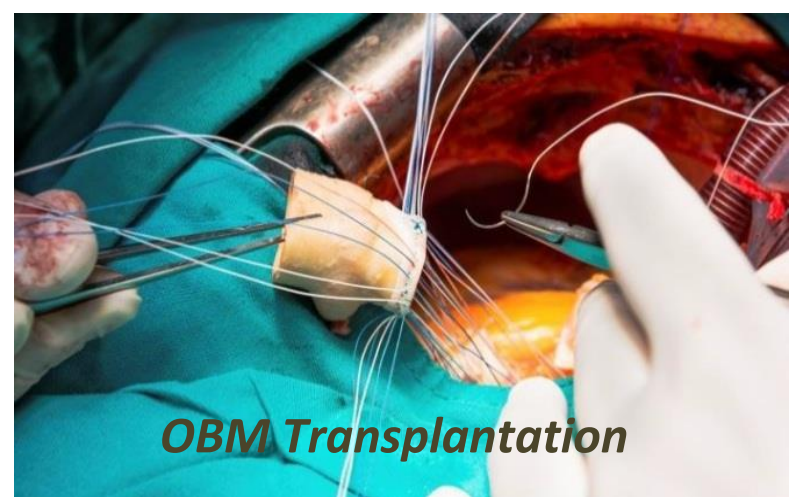

Enjoy OBM Transplantation by:

1. Submitting a manuscript

2. Joining in volunteer reviewer bank

3. Joining Editorial Board

4. Guest editing a special issue

For more details, please visit:

http://www.lidsen.com/journals/transplantation 